\title{
SOME INEQUALITIES INVOLVING OPERATOR MONOTONE FUNCTIONS AND OPERATOR MEANS
}

\author{
Mohammad Bagher Ghaemi And Venus Kaleibary
}

Abstract. In this paper we show that if $f:[0, \infty) \rightarrow[0, \infty)$ is an operator monotone function and $A, B$ are positive operators such that $0<p A \leqslant B \leqslant q A$, then for all $\alpha \in[0,1]$

$$
f(A) \sharp_{\alpha} f(B) \leqslant \max \{S(p), S(q)\} f\left(A \sharp_{\alpha} B\right),
$$

where $S(t)$ is the so called Specht's ratio, and $\sharp_{\alpha}$ is $\alpha$-geometric mean.

Moreover, we present some majorization and norm inequalities for operator monotone functions. Operator monotone decreasing functions are also discussed.

Mathematics subject classification (2010): 47A63, 47A64, 15A42.

Keywords and phrases: Operator monotone function, operator monotone decreasing function, operator convex function, $\alpha$-arithmetic ( $\alpha$-geometric, $\alpha$-harmonic) operator mean, Specht's ratio, majorization, norm inequality.

\section{REFERENCES}

[1] T. Ando, Concavity of certain maps on positive definite matrices and applications to Hadamard products, Linear Algebra Appl. 26 (1979), 203-241.

[2] T. Ando And F. HiaI, Operator log-convex functions and operator means, Math. Ann. 350 (2011), 611-630.

[3] R. Bhatia, Matrix Analysis, Grad. Texts in Math., vol. 169, Springer-Verlag, 1997.

[4] J.-C. Bourin, A concavity inequality for symmetric norms, Linear Algebra Appl. 413 (2006), 212 217.

[5] J.-C. Bourin AND F. HiAI, Jensen and Minkowski inequalities for operator means and anti-norms, Linear Algeb Appl. 456 (2014), 22-53.

[6] J.-C. BOURIN AND M. UChIYAMA, A matrix subadditivity inequality for $f(A+B)$ and $f(A)+f(B)$, Linear Algebra Appl. 423 (2007), 512-518.

[7] S. Furuichi AND N. Minculete, Alternative reverse inequalities for Young's inequality, J. Math. Inequal. 5 (2011), 595-600.

[8] R. A. Horn And C. R. Johnson, Topics in Matrix Analysis, Cambridge University Press, 1991.

[9] M. Tominaga, Specht's ratio in the Young inequality, Sci. Math. Japon. 55 (2002), 583-588. 